\title{
TREE SPECIES DIVERSITY IN SECONDARY FOREST OF VISAYAS STATE UNIVERSITY FOREST RESERVATION, PHILIPPINES
}

\author{
ANATOLIO N. POLINAR $\underline{1 l}$ and UWE MUUSS $\underline{\underline{I}}$ \\ 1/ Visayas State University, Baybay, Leyte \\ ขै Georg-August University, Goettingen, Germany
}

\section{ABSTRACT}

The study was conducted to determine species diversity and similarity within a two-hectare secondary forest of the Visayas State University forest reservation. The diversity value of trees ranged from $3.09-4.53$. Results of the study indicate that the middle layer of both blocks was observed as the most luxuriant among all layers. A total of 173 species, in 113 genera and 51 families; and 92 species, in 69 genera and 37 families were recorded in the middle layer of Block 1 and Block 2, respectively. The genus Ficus of the family Moraceae was identified as the most highly represented in terms of species in both blocks. Moreover, results of the study show that species richness increased with an increasing area but with a decreasing number of species. As to species similarities, it was discovered that $28 \%$ of the identified species are common to both blocks.

KEY WORDS: Species diversity. trees composition. similarity index. Shannon-Wiener Index. Ficus. species richness 


\section{INTRODUCTION}

Among life forms, trees are considered as the most important in a forest community and constitute a parcel of diversity in the tropical world. In Southeast Asia, it is usual to find more than a hundred different species of trees per hectare, excluding seedlings while some recent estimates suggest that occasionally, the total number of woody species maybe almost 400 per hectare (Longman, K.A. et. Al. 1987).

In terms of floral diversity, the Philippine forest is composed of at least 13,500 species, which represents five percent of the world's flora. It is estimated that flowering plants as between 8,000 and 12,000 species comprising 200 families and 1,500 genera; $20 \%$ of which is unknown while $27 \%$ to $75 \%$ is endemic. In trees alone, it contains about 8,120 species of angiosperms and 33 gymnosperms of which more than half of the species amounting to 5,832 are endemic. Of all the species types present in the country, trees belonging to the Dipterocarpaceae accounts for $66 \%$. Other families like Anacardiaceae, Ebenaceae, Verbenaceae, and Fabaceae are some examples of tree families that comprise the country's premium trees and constitute the remaining species proportion (PAWB, 1998).

One of the major global concerns about the tropical rainforests is the continued loss of biodiversity and their conservation. Secondary forests are expanding from time to time as forest continues to be intensively logged and converted into agricultural farm. The assessment of biodiversity is now gaining impetus for considerable research and actions. Researchers, policy and decision makers still have difficulty in coming up with updated information about the list of species and other relevant information.

An inventory of forest species in different regions is necessary to have improved information base so that management of the resources can be prioritized not only for their protection but also for their greatest conservation 
of Visayas State University (VSU) is of great contribution in vegetation and conservation studies in the future. There were few studies that had been made in LSU forest reservation but the area coverage is often limited.

The study was conducted to determine the tree species diversity and similarity between the two sites in the secondary forest of VSU forest reservation.

\section{METHODOLOGY}

\section{The Research Area}

The study was conducted in the forest reservation of Visayas State University (VSU), Baybay, Leyte. Of the total land area $(1,099.70$ ha.) of the University, the forest reservation covers a land area of 574.2 ha. The reservation is situated 8 kilometers north of the municipality of Baybay and $34 \mathrm{~km}$ south of Ormoc City (LSU Facts and Figures, 2003).

In terms of soils, Alisols dominate the lower slope of the mountain while Andosols are widespread in the upper slopes of Mt. Pangasugan. The lower parts of the landscape are dominated by Orthic acrisols with inclusion of humic acrisols and dystric nitosols. These areas are occupied with secondary vegetation, interspersed plantation and shifting cultivation farms. The soils are much more weathered, developed and less in nutrient status compared to Andosols (Asio,1996).

The climate in the study area is Type IV. It is characterized by frequent rainfall that is evenly distributed throughout the year. The average annual precipitation is $2,500 \mathrm{~mm}$ with a mean atmospheric temperature of $27^{\circ} \mathrm{C}$ (LSU Facts and Figures, 2003). 
The research site was composed of two hectares located between the coordinate system of $124048^{\prime}-124049^{\prime}$ eastern longitude and $10045^{\prime}-$ $10^{\circ} 46^{\prime}$ northern latitude. The first block was approximately N560E direction and $2,700 \mathrm{~m}$ away from the road junction that cuts across the University, while Block 2 is about N630E direction and 1,250 $\mathrm{m}$ in distance with respect to the same reference point. Both sites were accessible only by foot using farmers' established foot trail. Block 1 was situated far from the Kaingin farm and even to community compared to Block 2. The latter block is always prone to destructive human activities. considering that it was surrounded by human introduced developments. The soil in Block 1 was fertile as manifested by thick layer of humus and forest litter that favors development of vegetation, while in Block 2, humus and forest litter was limited and the soil is acidic. The terrain of the study area was from undulating to rugged and mountainous. The estimated average elevation was $80 \mathrm{~m} \mathrm{ASL}$ for Block 2 and $300 \mathrm{~m}$ ASL for Block 1. The slope gradient of Block 1 was steeper compared to Block 2 having a moderate slope orientation. In terms of vegetation, mixtures of closed canopy vegetation comprising commercial dipterocarps, premium hardwood and non-commercial species that included species of the family Moraceae, Verbenaceae, Euphorbiaceae, Mimosaceae, Annonaceae and Sterculiaceae.

\section{Site Selection and Sampling Design}

The research sites were selected based on the following criteria; 1) presence of a continuous 1-hectare secondary forest; 2) accessibility; 3) workability; and 4) future use value of the area with respect to further scientific, ecological and silvicultural studies.

Purposive sampling was used in the selection of the two sample blocks of 1 -ha each. The sample blocks were divided into 25 main plots. Each plot had a dimension of $20 \times 20 \mathrm{~m}$ with an area of $400 \mathrm{~m}^{2}$ (Aamlid, et al., 2002). Within each main plot, one subplot having a dimension of $10 \times 10$ meters (sub-plot $A$ and ten smaller subplots of $2 \times 2 \mathrm{~m}$ (sub-plot B) were established to monitor the abundance and presence of smaller size trees. The plot borders were surveyed and marked for future studies and monitoring purposes. 


\section{Data Collection}

The collection of data started in smaller sub-plots of each main plot to avoid damage of the small saplings or wildings. In sub-plot $B$, seedlings and saplings having a height ranging from 0.3 to 1.3 meters were identified, counted and recorded to document the species regeneration potential. in sub-plot $A$, the total height, abundance and frequency of saplings and poles with more than $1.3 \mathrm{~m}$ in height and up to $10 \mathrm{~cm}$ in diameter were counted, measured and recorded. Data on species abundance and frequency had been collected in the main plot for the analysis of its diversity. In cases where a specimen could not be identified by the researcher, sample specimens of good quality were collected for herbarium purposes and for species identification. The herbariums were brought to experts in Central Mindanao University (CMU), Bukidnon, Philippines for further referral and validation.

\section{Data Analysis and Interpretation}

The data collected from the field assessment were classified, tabulated and analyzed in accordance with the objectives of the study.

For diversity, Shannon-Wiener Index (Whittaker, 1972) as cited by Magurran, 1988) was used in determining the level of diversity of species between blocks. Three different diversity values were used to describe the extent of diversity in the area as shown below.

$$
\begin{array}{ll}
<2 & =\text { less diverse } \\
2-4 & =\text { diverse } \\
4-5 & =\text { highly diverse }
\end{array}
$$


Likewise, the Jaccard Index (Magurran, 1988) was used to find out the level of similarity among species within blocks. This was computed using the formula:

$$
C j=j /(a+b-j)
$$

Where:

$$
\begin{aligned}
& C j=\text { index of similarity } \\
& j=\text { number of species common to both sites } \\
& a=\text { number of species in site } A \\
& b=\text { number of species in site } B
\end{aligned}
$$

\section{RESULTS AND DISCUSSION}

\section{Families, Genera and Species in Different Sites and Canopy Layers}

A total of 139 species in 93 genera and 43 families were identified and recorded in the upper layer block 1 (Table 1). In block 2, there were only 80 species of trees in 56 genera and 37 families. Species belonging to the family Moraceae with genus Ficus was the most represented tree species in both blocks. Results showed that the species of Ficus were found not only within the study sites but also in a human disturbed secondary forest in Leyte. The other highly represented families in Bock 1 were Dipterocarpaceae, Euphorbiaceae, Meliaceae, Guttiferae and Annonaceae. Likewise, in Block 2, the families of Verbenaceae, Meliaceae, Euphorbiaceae and Burseraceae have been also associating with Turpinia ovalifolia. 
Table 1. Number of tree familises, genera and species in different canopy layer of the two study blocks.

\begin{tabular}{ccccccc}
\hline Canopy & \multicolumn{2}{c}{ Families } & \multicolumn{2}{c}{ Genera } & \multicolumn{2}{c}{ Species } \\
\cline { 2 - 7 } Layer & Elack & Black & Block & Black & Black & Black \\
& 1 & 2 & 1 & 2 & 1 & 2 \\
Upper Layer & 43 & 37 & 93 & 56 & 139 & 80 \\
Middle layer & 51 & 37 & 113 & 69 & 173 & 92 \\
Regeneration & 37 & 35 & 73 & 61 & 100 & 81 \\
\hline
\end{tabular}

Moreover, the results revealed the floristic differences in taxonomic composition of species between blocks. There were less species of trees in Block 2 than in Block 1 (Table 1). Both blocks are dominated by light- demanding pioneer species. One major reason for this situation might be the continued influence of anthropogenic factors on the distribution and composition of this ecosystem. The former is readily accessible for utilization by the human population considering its distance to the community. In effect, intense removal of valuable trees like Dipterocarps and other premium trees was done previously either by legal or illegal means. This supports the notion that once valuable trees have been removed from ecosystem, younger as well as older specimens of the logged species are often scarce (Longman, 1987). Seeds of trees are no longer available for natural regeneration resulting to a change in the floristic composition and structure of the species, which is somewhat different from that of the original vegetation. The presence of Shorea contorta in Block 2 might be the result brought about by the activities of various dispersal agents like introduction of species in the area through planting. A considerable number of domesticated and exotic tree species are also present in the area. These include Artocarpus heterophyllus, Albizia lebbeckoides, Gemlina arborea, Durio zibethus, Annona muricata, Swietenia macrophylla, Garcinia mangostana, and Coffea Arabica. The existence of these species in the site is an indication that block 2 had undergone an intensive change in its species composition due to a series of unending human activities. 
On the other hand, an impressive increase in species richness was observed in the middle layer of both blocks. An increase in the number of species and genus is noticeable in both blocks (Table 1). A slight change in the number of families is also prominent in Block 1, although in Block 2, no change has been observed. This is the result of the evolution of new species more particularly pioneers and opportunists brought about by the interaction and effects of various environmental factors that lead to their creation.

As to regeneration, a reduction in the species richness was observed in Block 1 but not so much in Block 2 (Table 1). The reduction or addition of species in a secondary forest is frequently possible considering the existence of innumerable factors that alter its growth and development. In particular, sufficient amount of viable seeds and suitable growing conditions must be available for regeneration to become established. It was observed in both blocks that regeneration of some species of trees is absent. If present, they are confined in a certain space and not evenly distributed over the entire area. Adaptation of species plays a significant role in its establishment in a given area at specific period of time. Not all species are adapted to grow in all kinds of vacancies that might be created. Others might be established under specific ecological niches and conditions of the sites. Sometimes, their establishment is even induced by some disturbances in the forest.

\section{Species Diversity}

The physiology of tropical forest is marked by the abundance of woody plants in a given area. Its abundance can be evaluated using the diversity value index. The index is another important value that has been used by ecologists for community studies, Higher species diversity value indicates a characteristic of a stable community. 
The species diversity value of the studied community ranged from 3.31 to 4.53 and 3.09 to 3.80 for Block 1 and Block 2, respectively. (Table 2). The highest diversity value was observed in the upper layer of Block 1 (4.53). The middle layer in Block 1 had the second highest value with a diversity index of 4.14 . Both the upper and middle layers of Block 1 indicate a highly diverse stratum. The lowest diversity index value was observed in the regeneration of Block 2 and implies that Block 2 (3.09) has a community that was less stable than in Block 1.This further indicates that Block 2 has undergone several changes in species composition as influence by any form of anthropogenic and atmospheric disturbances. Species diversity in both blocks was low in early stages of the plant succession but has suddenly increased and subsequently declined and remained more or less steady at a slightly higher level than it was found initially.

\section{Similarity Index of Tree Species Between Blocks}

The species composition across geographic regions or areas can be compared using similarity index. The Jaccard similarity index tells as to what percent the two habitats are similar in terms of species. Results revealed that both blocks have a species similarity index of 0.28 . This indicates that $28 \%$ of the identified species are common to both observation blocks. Hence, both sites had a generally divergent species composition.

Table 2. Diversity value in the two observation block

\begin{tabular}{ccc}
\hline Canopy & \multicolumn{2}{c}{ Diversity value index } \\
\cline { 2 - 3 } Layer & Block 1 & Block 2 \\
\hline Upper layer & 4.53 & 3.80 \\
Middle layer & 4.14 & 3.52 \\
Regeneration & 3.31 & 3.09 \\
\hline
\end{tabular}




\section{Species Accumulation Curve Between Blocks}

One of the most fundamental ecological associations that has important implication to the conservation of biodiversity is the relationship between area and number of species in a given plot. The association of an increased area with an increasing number of species has been tested several times not only for animals but for plants as well. It has been observed that if the plot area is increased, the number of new species encountered in a given place will likewise increase. However, the increase in the number of new species occurs at a decreasing rate. This is basically a result of recurrence of species in succeeding plots. Indeed, the species-area curve relationship remains the best criterion for the determination of the minimum study area.

Table 3 shows the information necessary for the determination of representative area needed for recording species composition. The above results provide information of the minimum area, number of new species and cumulative total frequency encountered in every plot. A total of 139 and 80 species were encountered in Block 1 and Block 2, respectively. The variability in the number of new species encountered in each plot is prominent. Results further show that the minimum area required for this study is reached at approximately less than $10,000 \mathrm{~m}^{2}$ for Block 1 and Block 2. The increase in the number of new species is less than $10 \%$ with a $10 \%$ increased in area.

In Block 1 , an increase in the number of new species was observed from plots 1 to 6 and a decrease in abundance from plot 7 onwards (Figure 1). Opposite trend holds true for Block 2 since a gradual increase in the number of new species was observed in all plots and more or less stable towards the end. This result validates the previous findings of some ecologists that species number decreases with an increasing area (Magurran, 1988). 
Table 3. Representative minimum area for recording tree species composition between sites

\begin{tabular}{cccccc}
\hline \multirow{2}{*}{$\begin{array}{c}\text { Plot } \\
\text { Number }\end{array}$} & $\begin{array}{c}\text { Plot area } \\
\left(\mathrm{m}^{2}\right)\end{array}$ & \multicolumn{2}{c}{ Block 1 } & \multicolumn{2}{c}{ Block 2 } \\
\cline { 3 - 6 } & & \multicolumn{2}{c}{ Species } & \multicolumn{2}{c}{ Species } \\
\hline 1 & 400 & 9 & 9 & 5 & 5 \\
2 & 800 & 14 & 23 & 5 & 10 \\
3 & 1,200 & 21 & 44 & 7 & 17 \\
4 & 1,600 & 14 & 58 & 5 & 22 \\
5 & 2,000 & 13 & 71 & 7 & 29 \\
6 & 2,400 & 10 & 81 & 3 & 32 \\
7 & 2,800 & 7 & 88 & 4 & 36 \\
8 & 3,200 & 3 & 91 & 6 & 42 \\
9 & 3,600 & 7 & 98 & 4 & 46 \\
10 & 4,000 & 8 & 106 & 5 & 51 \\
11 & 4,400 & 2 & 108 & 3 & 54 \\
12 & 4,800 & 0 & 108 & 2 & 56 \\
13 & 5,200 & 2 & 110 & 3 & 59 \\
14 & 5,600 & 6 & 116 & 3 & 62 \\
15 & 6,000 & 4 & 120 & 2 & 64 \\
16 & 6,400 & 1 & 121 & 2 & 66 \\
17 & 6,800 & 1 & 122 & 3 & 69 \\
18 & 7,200 & 1 & 123 & 3 & 72 \\
19 & 7,600 & 0 & 123 & 2 & 74 \\
20 & 8,000 & 4 & 127 & 1 & 75 \\
21 & 8,400 & 1 & 128 & 2 & 77 \\
22 & 8,800 & 2 & 130 & 0 & 77 \\
23 & 9,200 & 0 & 130 & 1 & 78 \\
24 & 9,600 & 4 & 134 & 2 & 80 \\
25 & 10,000 & 5 & 139 & 1 & 80 \\
\hline
\end{tabular}




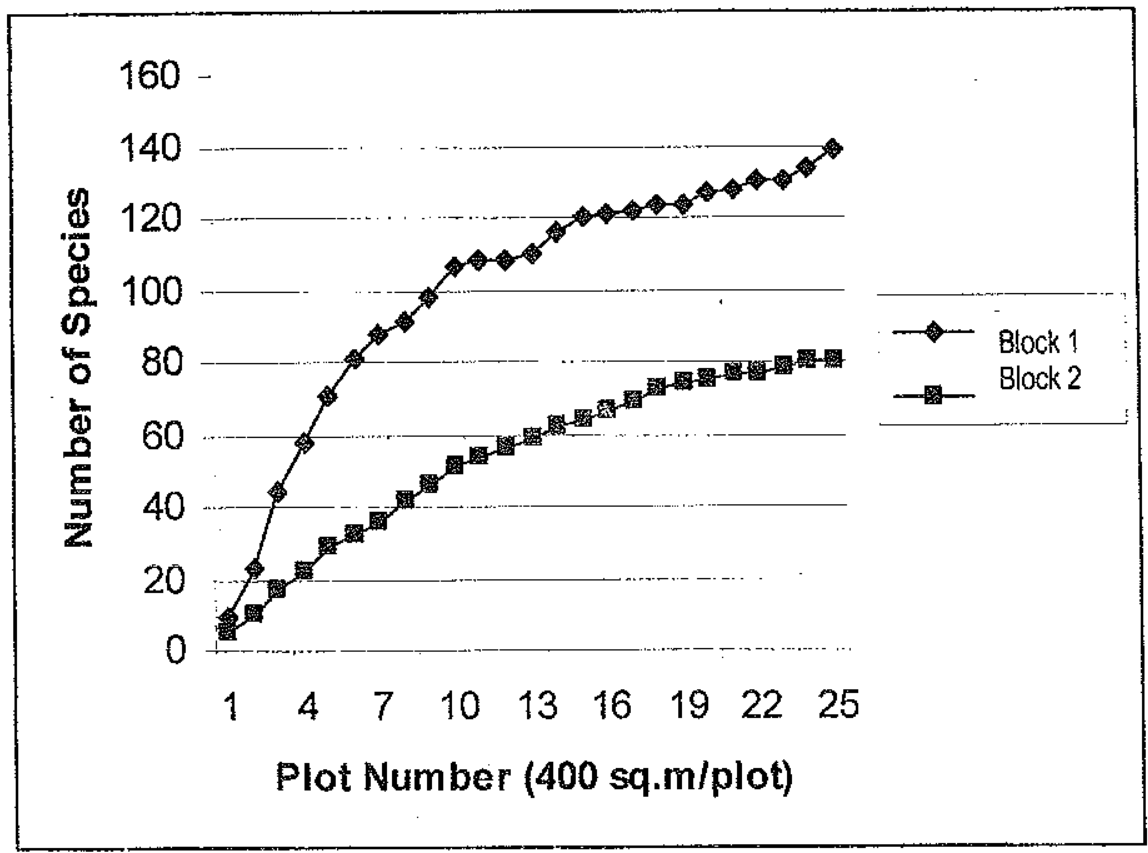

Figure 1. Species/area curve for Block 1 and Block 2 in LSU Forest Reservation, Philippines

\section{CONCLUSION AND RECOMMENDATION}

\section{Conclusions}

1. The two observation blocks harbor a diversified species of trees but mostly of light demanding pioneer species. The other highly represented families in Block 1 were Dipterocarpaceae, Euphorbiaceae, Meliaceae, Guttiferae and Annonaceae; while in Block 2, the families of Verbenaceae, Meliaceae, Euphorbiaceae and Burseraceae were also observed. The middle layer of both blocks was observed as the most highly represented in terms of species. 
2. Diversity and distribution of trees between blocks was mainly influenced by the destructive activities of anthropogenic factors that include illegal logging, shifting cultivation and wilding collection.

3. The number of species encountered increased with an increasing area but the number of new species occurs at a declining rate brought about by the reappearance of some species.

4. The genus Ficus of the family Moraceae was the most highly represented species in both observation blocks.

5. Secondary forest near village as in Block 2 suffered more floral impoverishment than forest situated far away from human population.

\section{Recommendations}

1. Intensive species inventory including other life forms should be conducted to have an overall picture on the level of floristic diversity.

2. Validation of the nomenclature of identified species and identification of unknown species should be conducted in order to have realistic value of diversity.

3. A continuing diversity research should be conducted to generate information and if possible, technology that are important for biodiversity conservation.

4. Study of edaphic factors should be conducted to determine their influence to the type of vegetation growing in specific blocks. 


\section{LITERATURE CITED}

AAMLID, D. Joakim Listad. 2002. Assessment of ground vegetation: A manual on method and criteria for harmonized sampling, assessment, monitoring and analysis of the effects of air pollution on forests. United Nations Economic Commission for Europe. 19p. ASIO, V.B. 1996. Characteristics, weathering, formation and degeneration of soils from volcanic rocks in Leyte, Philippines. Institute fur Bodenkunde Und Standortslehre, Universitat Hohenmeim, Germany. Hohenheim Soil Science Issues. 1(33):1. 209

HOBBS, R.J. D.M. RICHARDSON AND G.W. DAVIS. 1995. Mediterranean-type ecosystems: The function of biodiversity. Ecological Studies 109(1):1-42

LONGMAN, K.A. and J. JENIK. 1987. Tropical Forest and Its Environment. 2nd Edition. John Wiley and Sons, Inc. New York. $347 p$.

LEYTE STATE UNIVERSITY. 2003. LSU Facts and Figures. Leyte State University, Visca, Baybay, Leyte, Philippines. 40p.

MAGURRAN, A.E. 1988. Ecological Diversity and its Measurements. Croom Helen Ltd., London. 179pp

PROTECTED AREAS and WILDLIFE BUREAU. 1998. Philippine biodiversity country study. Philippine National Project Report to the Convention on Biological Diversity. Protected Areas and Wildlife Bureau. Department of Environment and Natural Resources. 86pp.

SAJISE, P.E. 1997. Biodiversity in the Philippines Terrestrial Uplands: Status, Issues and Research Agenda. Paper presented during the National Workshop on Agenda Setting for Biodiversity Research in the Philippines, 2-4 July 1997. SEARCA, Los Baños, Laguna, Phillippines 


\section{ABOUT THE AUTHOR}

The author obtained his Master of Science (M.S.) degree in Tropical and International Forestry at the Georg-August University, Goettingen, Germany under the German Academic Exchange Program (DAAD) scholarship grant in September 2004. He is presently connected with the Department of Forest and Wildlife Management and Conservation of the College of Forestry and Natural Resources of the Visayas State University, Visca, Baybay, Leyte.

The co-author is the managing director of the University Centre for Tropical and Sub-tropical Agriculture and Forestry in Germany. 